\title{
A Review of Eva M. Simms' The Child in the World: Embodiment, Time, and Language in Early Childhood
}

\author{
Andrew Foran, St. Francis Xavier University (Antigonish, Nova Scotia, Canada) \\ Email contact:aforan@stfx.ca \\ Elizabeth Munroe, St. Francis Xavier University (Antigonish, Nova Scotia, Canada) \\ Email contact: $\underline{\text { emunroe@stfx.ca }}$
}

How does the non-child enter into this complex yet wonderful world of childhood? Ironically, this world of children is all around us, but not easily entered. Adults tend to observe this world, rationalize and surmise via a mature perspective as to what is occurring for children, but how much of this world can we really understand-even see or feel? Eva Simms attempts to lead the professional adult and parent into the mysteries of the lived experience of the child in the world through a series of crafted chapters that provide windows for us to glimpse the possibilities of child dwelling: Milk and Flesh, The World's Skin Ever Expanding, About Hens, Hands, and Old-Fashioned Techniques, The Child in the World of Things, Playing at the Edge, Because We Are the Upsurge of Time, Babble in the House of Being, and The Invention of Childhood. Each thematic section reveals an aspect of what it means to be a child by offering a special element, the unique of children's lives in an adult world.

Simms manages to raise awareness of a child in the world by challenging our interpretations of children, but her portrayal and our understanding may still not be a child's experience. Despite every adult living through what we define to be childhood years, to be a child is understood reflectively through adulthood. Thus childhood is by far a taken-forgranted and a culturally commonly reflected experience-nostalgically or academically. We all tend to remember our past times as a child growing up, yet, I have discovered that an adult can only enter this world reflectively, for the grown-up can never really be in that world. Why? For the very reason adults admire and are fascinated by children: their ability to be fully in a moment. Children know how to live in the here and now without regrets. For an adult to enter that world would require the adult being able to let go of the everyday and embrace living in a moment. Children demand far too much of their world to dismiss wonder and adventure even in the smallest of things. Reflectively, I tried to renter the world of my youth by recalling an everyday task, a taken-for-granted: going outside.

Children rarely seem to just walk. Children burst into the outside world. The child's entrance into the outdoor world is typically accompanied by speed, noise, and smiles. We see this scene depicted in the movie Small Change, by Truffaut (1976). The school door flies open, seconds after the ringing of the final bell, and we see and hear the noise of rushing children to get out. In a magical blur, the world is full of children pouring into the open space. It is a moment that defies belief, for more children per second can navigate the narrow streets of the old French village than would seem physically possible. Within seconds the 
streets are emptied and the school is silent. It is as if the outside has unconditionally accepted the presence of children and has made room for their infinite energy.

Small Change effectively entices adult viewers to remember what it is like to be a child in the closing weeks of the school year. Truffaut (1976) does a marvelous job catching their spontaneity in the classroom, during recess, on the street, and at home. He provides vignettes of the children from the provincial town of Thiers, in France, but it is the scenes of children in the episodes outside the containment of school, at day's beginning and end, when viewers see just how enthusiastic children can become. After viewing Small Change, I recall memories of my own childhood and the desire for the freedom that I experienced outside the school. I could see myself in the children of Small Change as they leave their school or move through the streets of their small town, they are in constant motion, a mass of bodies in uncontrollable flux. The outside world fuels their laughter, their screams-their legs pumping faster then the pistons of an engine, and arms swaying, waving, and flapping with passion and enthusiasm; one could swear they are about to lift off in flight. Adults do not leave buildings in this manner. Do adults ever go out like children: free, full of energy, and without a clearly defined purpose? As we get older, I wonder sometimes whether the outside becomes a world that is foreign to us. Would it be possible for grown-ups to regain a sense of being a child outside? Yet for many adults there is still a pull, a call, and for some there is a dominance that the outside seems to have over their consciousness. Many of us, adults or children, need the outdoors to make sense of our lives. This understanding presents itself in simple life lessons.

\section{Going Outside}

"Where are you going?"

"I am going out."

"Where?"

"Just out."

"What are you going to do?"

“I don’t know. I’m just going out.”

Children sometimes make reference to going out to play or to just going out. For children, going out may be the opening of the real or imaginary world of adventure, exploration, discovery, games, and play, or it may be merely puttering about.

When I was a kid I couldn't eat breakfast fast enough. The only thing I wanted to do was go out! I never had an agenda; I don't think I even had a plan. I just went out and things happened. When the last of the cereal was gobbled down it was the dash for the ratty-old black and white Converse-they were the fastest sneakers. I would be at the furthest allowable limit on the back lot before the back screen would hit the doorframe. This is where I became a kid. Thinking back, I still do not know if I really did anything. I would touch, smell, listen, and see the outdoors. I was an outdoor kid living and seeking imaginary adventures: everything was possible. I would sit by the brook, pick up sticks for hours of water racing, gather last year's leaves, move rocks to catch a glimpse of what or who lived under them, wander the waist-high grasses at the yard's edge, and go from one interesting thing to another. I was constantly fascinated with nothing, everything. Hours could slip by while I was watching the ants hustle over their hill. When the birds were nest building 
they never minded my presence; they would land close by for twigs, grass, and mud-balls made by the night crawlers. I was always at home, at peace in the back lot. When Derrick came over, we were the best friends at doing nothing. Sometimes we would just layback looking up at the confusion of clouds. Nothing mattered here. When I was alone I would just sit in the grass. Just sit. The outdoors was my constant friend. Somehow this childhood friendship slipped away. There was one day when I stopped going to the back lot to do just nothing. I wonder why?

How a child spends time in the outdoors or even goes outside is removed from how adults spend time outside. The outside is where adults reinvent themselves but outdoors is where children find themselves.

Simms challenges the adults' perception of what it means to be a child by removing adult constraints by helping us to see the child's world phenomenologically. Simms presents a range of everyday experiences that draws the professional in for a deep and rich understanding. We have phrased this a sensitive knowing, for the child's world is one that must be cared for pedagogically.

\section{A Reflective Snapshot}

Douglas is three. He and I have just returned from buying a few groceries and borrowing some books from the local library. We enter our house through the side door and we remove our boots and jackets. I take the grocery bag up the two steps into the kitchen. I ask Douglas to take off his rain pants and then to bring the book bag up into the kitchen. As I start to put the groceries away, I glance into the side hallway. Douglas is completely absorbed in looking through one of his library books. The book is open on the edge of the kitchen floor. Douglas' head and arms are also at the edge of the kitchen floor. The rest of his small body is casually draped down the two steps. One of his legs is free from the rain pants, but the other leg is still clothed in the bright yellow outerwear. I reach for my camera and take a photo of this child in the world.

Why do I snap that picture? Perhaps it's a reflection of my admiration (and appreciation?) for a child's ability to be in the moment, to abandon a task and be absorbed in something immediate and of more interest. I, as the adult, am more task-oriented. I have delayed the gratification of relaxing with my library books until my "work" is done.

The child has a different way of being in the world. As adults, we might respond to this different way of being with frustration and maybe even anger, because the child is not following our intention for the child being in the world. At other times, we admire and are even a bit jealous, perhaps, of the child's way of being in the world. We write poems or create sayings that portray something of the adult's wish to experience that childhood abandon, joy, focus or wonderment once again. "When we are children we seldom think of the future. This innocence leaves us free to enjoy ourselves as few adults can. The day we fret about the future is the day we leave our childhood behind” (Rothfuss, 2007). 


\section{Child Dwelling}

Maurice Merleau-Ponty, in The Sorbonne Lectures 1949-1952, affirms the continuous need for pedagogical reflection that reveals the adults' views of a child. Van Manen (1982/1991/2002/2006) teaches us that pedagogical reflection allows an adult to be in a moment of truth, a knowing of what is wanted without constraint. For any adult with children, this special way to reflect is a demonstration of a pedagogical attitude that presents moments as significant encounters steeped in sensitivity. Van Manen's work has shown lived experiences, concrete moments - encounters with a child or young person-as lived meaning revealing a felt sense, a bodily knowing, an attunement of a mutual relationship. Heidegger (2001) claims attunement is realized only by being with others; being in their presence fully. Van Manen reminds us this is a tactful expectation for any adult to be fully there for children.

Simms' book appears to us to be about adult attunement (Heidegger, 2001) to the child's dwelling in the world. As Simms writes, "We have only to learn how to see it" (p. 77). In reading the book, The Child in the World, and thinking about child dwelling, we found there were passages that left us questioning, reflecting, and wanting to discuss (with other adults or children) the significance of the experiences, and there were passages that left us just wanting, unsure, uncertain, and in need of more phenomenological experiences in order to see what Simms is asking of us to do. Thus we have posed questions that are linked to each chapter and have invited Simms to respond to our discussion as an open dialogue to further her work. Hopefully this conversation with the author will deepen the interest in her book and enhance the seeing of childhood worlds.

\section{CHAPTER 1: Milk and Flesh - Infancy and Coexistence}

A baby nursing is the primal event Simms offers to begin to reveal the child's world. Simms describes the mother and the child as one and at one with their world. Reading this chapter presents an experience that I struggle to glimpse as a man; I could never share this level of intimacy with my children nor can I capture reflectively "being housed in the circle of maternal space” (p. 13). I can recall watching my own children in this coexistential form of "mouth and gaze" and see anew what Simms is trying to help me see: suckling is an immediate experience for the infant to reclaim the nourishing cradle of that inner world.

I realize after reading this chapter that this simple expression of life-giving is more that a biological feat - there is a profound intimacy that is hard to capture by words and I may never find the words to fully capture this experience. However, Simms allows me to access, even in a limited way, the experiential of this shared experience by affirming that the world for children waits for our touch and that is an unconditional experience. For even as the infant is entwined with his mother, the child will "sacrifice" this relationship (Jager, 1999, p. 76) to move beyond the milk and flesh and enter into the world through "places, people, and things" (Simms, p. 24).

A number of times in this chapter, I stopped reading to consider the bond that is shared and formed and know this is an experience I will not likely have in my life, but can I see the potentiality of this lived moment between a mother and babe?

QUESTION: How can adults access such a private world where the foundation of existence is on unconditional giving: milk for life? We include the mother in this for I am sure she knows more of her child's world intuitively. The import of this question rests on mothers who decide or cannot breastfeed and males who in this experience can only be participant observers to degrees. 
EVA'S RESPONSE: I would like to respond with a quote from Bachelard (1983), which ties together the experience of the gifting/receiving of milk for the infant with an adult experience that can approximate it: "Has milk not overwhelmed us, submerged us in a boundless happiness? In the spectacle of a heavy, warm, productive summer rain one might find the living image of a downpour of milk” (p. 123).

In a radical Merleau-Pontean reading of child experience we see psychological life not as an internal, private event, but as a way of being in the world. "My consciousness," Merleau-Ponty (1964b) says, "is turned primarily toward the world, turned toward things; it is above all a relation to the world" (The child's relation with others, pp 116-7). This means that the preverbal child's experience is accessible to adult consciousness (however incomplete) through a careful analysis of the world structures (space, things, time, others) in which it displays itself. The phenomenological method-through attentive description and analysis of the phenomena of a child's life-attunes the researcher to the web of coexistentiality, embodiment, spatiality, and temporality and with it to the child's elemental experience of her or his world.

In general, I see the phenomenological exploration of aspects of the child's world as an attempt to approach the pre-verbal, pre-reflective dimension of human experience in general. The infant's experience of milk (and everything that surrounds its presence in the child's life) is an early form of comfort/contentment/nourishment which metamorphoses in a person's life into other forms, such as snuggling with Daddy in the big chair while reading a story, hiding under the covers while reading a book with a flashlight, stepping into the comforting arms of a friend, gathering family and friends around the dinner table, finding oneself in the warm downpour of a summer rain, or having the sense of being welcomed by a familiar and beloved landscape. Feelings are not internal, private events, but they are spread out over the spaces and things and people the child (and the adult) encounters. The boundless happiness of milk is in the arms, the scent, the warmth, the fluid, the fullness of the situation - be it in the arms of one's mother or in the Earth's gift of a warm summer rain.

\section{CHAPTER 2: The World's Skin Ever Expanding - Spatiality and the Structures of Child Consciousness}

Simms suggests that the unconditional experience of milk and flesh contributes to the infant child's growing confidence with the stability or dependability of the world: "the sense that the world is not chaotic but fundamentally ordered because of the coherence and inherence of things” (p. 22). In her second chapter, Simms explores the child's experience of space expanding from the uterus, to the infant's "kaleidoscopic" experience of people and things, to the perspective from an upright posture and mobility towards the beckoning world, into dark spaces and secret spaces. Simms invites us, as adults, to pause to consider the child's nondualistic experience of space and spaces, and she leads us to respect the child's sensitivity "to the moodedness of a place, its quality of openness or secrecy, danger or coziness, excitement or tranquility" (p. 45). Simms leads us to ponder about the way in which children "perceive and realize some of [the world's] dimensions that are hidden from most adults" (p. 51).

Of great interest to us was Simm's strong support of children having the opportunity to dwell in "undetermined" spaces. Simms declares that "A childhood that takes place in a completely adult-determined spatiality is 'personally malnourished,"” and that "children need open, undetermined places to truly have a childhood” (p. 57). Simms sentiments are echoed in Louv's (2008) recent book, Last Child in the Woods and are reflected in such current initiatives in early childhood education as forest pre-schools and the movement now titled, 
“Leave No Child Inside.” The World Organization for Early Childhood (OMEP) had, as its primary conference theme in Sweden in August 2010, "Early Childhood Education as a means of moving towards Sustainable Development of the World" and many presenters were focussing on children developing a sense of stewardship for the world through experiences in undetermined spaces.

QUESTION: Simms mentions that "by more and more restricting the undetermined places where our children play ... we are limiting the child's ability and initiative to create a future world that has depth, fullness, and compassion” (p. 58). There is a growing number of parents and professionals, world-wide, who would agree with your emphasis on the importance of children's dwelling in undetermined spaces. Louv has even raised the spectre of Nature Deficit Disorder (NDD). What is your reaction to this turning of adult attention to the potentiality of children dwelling in secret and undetermined spaces? Do you pause at this?

EVA'S RESPONSE: Childhood is always and only childhood in relation to adulthood. Adults create the world into which children are born, and we shape childhood to fit into the forms that our adult culture assumes. Childhood is radically historical, as I tried to argue in the last chapter of the book, and dialectically related to how adults experience themselves and their society. However, forms of childhood are also not fixed, and the future can be shaped differently.

I am very happy with Louv, Sobel, and others who point out that in the past 20 years the state of childhood has changed radically, and my own research has also confirmed this (Simms, 2008b). We witness a shift in children's lives in the US from a communal, outdoors, peer centered life with adults in the background to a childhood today primarily lived in adult organized and determined activities, such as schooling, sports and cultural activities, computer games (also designed by adults) and supervised indoor play dates. We are coming to a point in the self-understanding of our culture where it seems perfectly natural to keep our children close to adults and indoors all the time and to curtail the development of an essentially childlike agency and initiative. We justify this by saying that our public life is too dangerous for our children to be out there in woods and neighbourhood streets with their friends and siblings: some "creep" might come and abduct them. The reality is that while the anxiety rates of American adults have steadily gone up over the past four decades, the actual crime rates have gone down significantly. Louv's Nature Deficit Disorder is not only a problem of children, but a problem of how adults feel about our culture. I welcome it when adults become aware that by eliminating the undetermined places and activities in our children's lives, we are also are re-shaping the future of our culture - and not for the better. Children who are not exposed in their play to the varieties of natural forms and processes are intimidated by natural spaces when they grow up. The woods and green spaces are undifferentiated "green stuff" which is threatening and frightening. Adults with nature deficit disorder have no empathy and interest in nature, and any appeal to their emotionally cold "environmental responsibility" remains abstract and ineffective.

As a parent today I have to continuously protect my children's agency and initiative and their right to undetermined, adult-free spaces and be aware that I can make choices against the prevailing neurotic parental anxiety that pervades our culture and myself. I can choose to let my children play in the woods without me, and I can try to protect their undetermined spaces (even from myself). 


\section{CHAPTER 3: About Hens, Hands, and Old-Fashioned Telephones - Gestural Bodies and Participatory Consciousness}

Simms presents chapter three as a detour where the reader can "arrive at a new appreciation of children's drawings” (p. 59). Growing up with two boys has taught me, as an educator, father, and person making sense out of the every-day world, that a child's visual representation is more than art; it is a gentle view of their world. As in our opening for this review, we distinguished that children are different from adults-beyond age and maturation-most significant in how they view the world, but more significant how they are so open to the world. In this chapter Simms is clear in her intent to show the child's world as distinct through drawings and these distinctions may even be contradictory to the lived experiences common to the adult world.

The experiences shared artistically in The Child in the World, are based on how children have come to understand their worlds through direct experiences. Simms presents examples of how children tend to freely draw and distort "meaningful spaces" (p. 60), even ignore accuracy in order to capture what a visual means. The illustrations reveal how children viewed their bedrooms as more than "geometrical extensions" (p. 64) of their world to their family and she points out the child's "disregard of anatomy" (p. 65). Simms helps us to see beyond the infantile of these illustrations and suggests they are not unsophisticated; rather she compares them to medieval art:

I think that children's drawings can be understood more clearly when we look at representations of space and body by people who do not share the materialistic assumptions about the nature of space and body that have developed in the West since the Renaissance. (p. 65)

Dwelling in the possibilities of what is hidden or revealed in a child's world because of what they drew raised many interesting possibilities - the pictorial space is a rich source of meaning and a world that is without doubt distinct from the adult's experience.

Chapter three is more than a reminder of how a child captures the world through illustrations. I firmly believe the picture is a rendering of experience and that like the anecdote in phenomenology is their lived experience. Simms states that "young children often surprise adults when, with one brief phrase or gesture, they shatter our habitual assumption that they experience the world as we adults do" (p. 70). Children disrupt the everydayness only to reveal the world anew if adults take the time to dwell in their artistic representation. In order to achieve this, we must, as Merleau-Ponty (1964) encourages, not see the child as a miniature adult. Simms furthers this in the following, "take the child's consciousness as a positive phenomenon and explore it on its own terms" (p. 74). Again, I have learned much about the world through the art hanging on my own fridge. There are times in the development of children when there is an abundance of illustrations: some very clear in what is being illustrated and others works of art that require brilliant interpretation that only children can provide.

QUESTION: In this chapter, you remind us about the symbolism currently attributed to medieval artists' works, and you invite your adult readers to re-think their initial dismissal of children's art as immature and imprecise. We wonder, however, if you are leading us, as adults, to attribute unwarranted meaning to children's art. A young child drawing a hand holding a watering can is presented with a technical problem: How does one show that the hand is holding the can? Perhaps the child has merely solved this problem by intertwining the fingers and the watering can. Perhaps the child does not see the hand and the watering can as 
"one." Perhaps the child's drawing has no implication at all that the child "does not yet accept the hand as a purely anatomical appendage completely separated from the inanimate objects out there" (p. 67). Is there any possibility that you as writer and we as readers and adults with heightened awareness of child dwelling will attribute a "surplus of meaning" (p. 70) to the child's actions and artifacts?

EVA's RESPONSE: My attempt in this chapter was to vindicate the expressive activity of the child against the constructivist, cognition centered view of childrens' drawings, which sees them merely as failed adult products. I have looked at hundreds of childrens' drawings over the years, and it is obvious that children do not "copy" reality, but choose what to present on paper. What is there has significance. Let me give you a beautiful example from Louise Chawla's work with children in a South African Squatter's Camp. Chawla (2003) asked children to draw pictures of their homes, which were mainly shacks built out of scrap lumber and cardboard. The 10 year olds drew the insides of their homes with much care and great attention to specific details. Many of the drawings had gardens with plants growing in them. However, when the researchers checked, there were no "real" gardens to be found in the camp. The "imaginary" gardens were in the pictures because the children felt that their homes were beautiful and that things flourished there. Would you argue with the children of the squatter camp and tell them that their pictures are wrong because they did not copy the visible, agreed upon, conventional space of the adult? Phenomenal space, i.e. the space of experience, is not limited to mathematical coordinates, but shot through with the warp and weft of meaning. If we as adult researchers want to understand children's artwork we have to bracket and deconstruct our cultural assumptions and expectations of what we are supposed to see in a representation. We have to work hard at being open to see otherwise.

\section{CHAPTER FOUR: The Child in the World of Things}

Simms begins this chapter by helping us to differentiate between the term object and thing. She explains that the German connotation of the word thing "refers to a gathering, a coming together, while the Latin word objectum describes what stands opposite or against us" (p. 82). Simms' description and distinction between the terms helps us, as adults, to consider in a different light the young child's relationship with things. We are invited to think again about such terms as "object permanence" and "transitional object." Do babies appear not to have object permanence because they are attributing meaning and giving their attention to the adult's manipulation of the hide and seek toy, rather than to the toy itself? If that is the case, the baby's lack of focus and interest when the object is removed is not an indication of a lack of understanding of permanence. When the object is removed, the play script with the adult is over. And, let us consider the favourite blankie. If we, as adults, term the blankie as a transitional object, we may have difficulty being empathetic to the child's attachment. But, if we term the blankie as a transitional thing, we may reconsider the meaning that the blankie holds for the child. As Simms explains, "a transitional thing is not an enclosed object but a field of meaning that varies in the context of an infant's relationships with his or her caretakers and the spatiotemporal arrangement of sleeping and comforting patterns in the family" (p. 97).

In this chapter, Simms helps us to understand the growing child's dwelling in a world of things. She examines Piaget's writing about the nondualistic, participatory or magical realism that is evident in young children's relationships with things. We are reminded of the wonderful children's story written by Williams (1922), The Velveteen Rabbit: Or How Toys Become Real. As a new member of the nursery, the velveteen rabbit asks the more 
experienced toy horse about becoming real. The Skin Horse explains, "Real isn't how you are made .... It's a thing that happens to you. When a child loves you for a long, long time, not just to play with, but REALLY loves you, then you become Real” (para. 6). As the story unfolds, the boy and the rabbit share numerous exciting and close times. When Nana grumbles about how shabby the toy rabbit is becoming, the boy exclaims, "He isn't a toy. He's REAL!" And, by the end of the story, the Fairy makes the rabbit real in terms an adult can understand - that is, the toy is now a rabbit living in the woods with other rabbits. The velveteen rabbit wanted to be real, the boy exclaimed that it was real, and after the rabbit serves an important comforting role during the boy's illness, a fairy confers living status on the rabbit. Simms attributes Piaget as concluding that "children's cognition is not merely alogical thinking; rather, it arises from a different experience of the world” (p. 103). Adults who read Simms' book will surely pause, remember their own childhood things, and think differently about the things in the lives of the young children they know.

QUESTION: Simms writes that children "live in a fuller slice of the plenum which, on their way to becoming Western adults, is gradually reduced, redefined and mostly made unspeakable” (p. 103). My brief experience living in an Eastern culture (Malaysia) gave me some glimpses into the widely held belief and reliance on bomohs or shamans that breathes alongside the Muslim religion of that country and co-exists in that increasingly westernized society. We wonder if Simms has some additional comments to share about the "Westernness" of living in a diminished slice of the plenum.

EVA'S RESPONSE: From the first days of an infants' life the world is inscribed in the body. The shapes and colors of their home, the language of their families, the scents of a culture's cuisine, the gestures of the adults, the things in the child's reach form the child's perceptual world and prepare the human brain to be responsive and function well in this particular environment. Brain plasticity means that the human body prepares itself to "fit" better and better into its experienced world. Different cultures shape the child's perceptual, emotional, and cognitive abilities in different ways, some of which are indirect and unreflected (such as food, environmental structure, and gestural communication), and others that are intentionally taken up and transmitted to the child (education, customs, religion).

One of the most significant intentional changes that Western culture has introduced to children since the late renaissance is textual technology: Western children have to learn to read and write, and I have shown in another study (Simms, 2010) how this textual technology re-structures human consciousness. Since the pervasive adoption of textual technology (and I mean technology here with all the advantages and dangers in Heidegger's sense) the educated Western mind lives in a virtual, text transmitted reality most of the time, and children spend most of their time from the age of five to twenty-one being induced into and having commerce within this virtual symbolic world. The effect of textuality on child consciousness is a reduction of the awareness and knowledge of the sensory, perceptual, and bodily aspects of the world. But it also adds the richness of the symbolic world of a culture: its science, its literature, its history.

Cultures differ in the amount of virtual textual reality that they give their children. Many still transmit their cultural knowledge and religious practices through direct oral discourse and practical participation in daily tasks with adults. Children attuned to the natural world through working alongside adults have a greatly differentiated perception of their particular world: the Baka children of New Guinea know exactly where and when to find the snails in the rainforest and how to climb the trees to get them. Literate, western 10 year olds know the layout of Hogwarts and the rules of quidditch: their commerce is not in snails that will be 
cooked and eaten in a communal setting, but in ideas and experiences produced by virtual textual realities and increasingly shared through other virtual media.

\section{CHAPTER FIVE: Playing at the Edge - What We Can Learn From Therapeutic Play}

Simms, drawing on Rousseau (1762/1979) states that "play is the child's work" (p. 109). Despite our disagreement with this definition of play, we both found the chapter to contain interesting elements of how children learn through formalized adult structures: preschools, kindergartens, elementary and middle schools. The thrust of Simms' discussion is how formalized learning is cutting into the heart of what it means to be a child—play. Play, in our view, is the natural manner in how children are in this world. We agree with Simms that the proliferation of texts and programs with an academic focus for young children has diminished genuine or quality experiences for children. Missing is free play, not play structured by adults, but play that is entered into and created by children free from adult intervention.

Simms presents a very child-like example to demonstrate how play is a child's expression of self in the world: play "entails direct experience, which in turn deepens the child's self awareness" (p. 112). Simms continues by claiming that play is a precondition in the "ability to experience the multiple possibilities for engagement inherent in things. This openness sets play apart from other human activities such as work or structured learning” (p. 112). Simms solidifies her position on the importance and value play has for the development of children when she brings Gadamer (1996) into the discussion by stating play is "where agency and selfhood are exercised without direct annunciation of the self" (italics in original, p. 113).

We both agree with Simms that play is the engagement of possibilities that can be discovered within a child's immediate world-imaginary or physical. Simms leads us through a complex set of what is possible when the discussion turns to symbolic play: "an expression of human curiosity and a striving for knowledge that transcends spoken language" (p. 119). Simms captures the richness of the experiential for children in this form of play as an act of creationism, but we tend to see play not only as an exploration that embraces a " "physical world' out there;" rather, play is a response to the world's invitation to engage. And it is for this very reason that children are able to live fully in a moment.

QUESTION: You claim that adult structures potentially can stunt or halt the natural progression of a developing child in "our rush to teach our children academic skills, especially reading” (p. 124). However, we are curious to how you would respond to developing literacy through sharing with children quality literature, that potentially has the power to release a child's imagination to embrace more that what is possible. Is not the world of imagination essential for children and does not the imagination often define what it means to be a child?

EVA'S RESPONSE: I think it is a mistake to equate imagination with textuality and the production of fiction for children. The imagination is already active in the symbolic play of the very young child, and the socio-dramatic play of four year olds can be varied, profound, and - under the right circumstances—sustained over many days. We know from a number of studies that this kind of social imaginary activity allows children to regulate their emotions and become more easygoing in the classroom. Child play is one of the great testimonies to the power of the human imagination to see the possibilities inherent in things and to create and enact virtual realities. 
For young children there is little difference in what inspires their play: superheroes watched on television, story characters from books that adults read to them, or knights and princesses from stories told by an adult. The child's imagination takes up the themes that are appealing and needed for forging a sense of identity. The question is not if children have their own imagination, but how adults should relate to it: can we give children characters, images, and plots that satisfy them on an emotional level, but that also help them deal with the disturbances and difficulties of their worlds? The power of stories, as Aristotle already articulated, is that they have a plot (mythos) that transforms us on the emotional level (metanoia), and as adults we should be aware of the power that fiction has over the child's emotional life. Reading, as I mentioned above, is not merely an innocuous little skill that young children learn. Literacy is a textual technology which profoundly re-structures human consciousness on the personal and on the cultural level. Responsible adults and educators need to be aware of the psychological impact of literacy/textuality and choose when and how it should be introduced to the child's mind.

\section{CHAPTER SIX: Because We Are the Upsurge of Time - Toward a Genetic Phenomenology of Lived Time}

Simms writes about clock time and lived time. She makes reference to cultural differences about time and Piaget's work on children's development of a sense of operational time. She leads the adult reader to look at a child's dwelling in the world, in terms of the past, the present, and the future and she helps the adult understand time in a new way. Simms states:

In lived time past, present, and future overtake each other, reverse their order and weave together their intricate web of becoming. The past is nothing without the future, the present does not exist without the past, and the future determines how we experience the past and the present. (p. 134)

We especially appreciated the ideas underlying the following memorable statements of Simms. She writes, "A toy is an invitation to step into the future" (p. 146) and "The more determined a toy is, the less future is in it; it allows only the future already prestructured by adults to emerge" (p. 147). Here we thought back to ideas that had significance to us in previous chapters of the book about space, play, and things.

Although we agree with Simms' thesis that children may understand time differently from adults, we warn against adult mis-interpretation of children's use of time-related words as evidence that children understand time differently. We would like to make a distinction between a child's use of a word and a child's possible intention in using a word. Simms' relies heavily on one child's use (mis-use?) of the word "afternoon." The child in Simms' example seems not to understand the temporal connotation of the word "afternoon." But, perhaps that child understood the word "afternoon" more as an event than a description of part of a day; thus, the use of the word had little to do with the child's understanding of the passage of time. I once had a young student say, "Is this today?" I found that to be a most astonishing comment and I pondered what the child intended by it. I eventually realized that all week I had been promising the children that the fire truck would come on Friday to take them for a ride. Then, on Friday morning, I said, "Today the fire truck is coming to take you for a ride.” That is when the little boy asked, "Is this today?” Maybe an adult rephrasing of his question would be, "Is this the day?" My younger son once said to his older brother, "When I'm older than you, I'm going be the one to go first.” I would suggest that comment was more about what "being older" signified than a mis-understanding of time. 
QUESTION: Although most adults are aware of clock time, we all (we suspect) have had the experience of time seeming to speed up, or slow down. So many phrases are common in our culture regarding this kind of experience of time: "The time just flew by" or, "Time stood still." Csikszentmihalyi (1990) has researched and written about the phenomenon of "flow" in adult lives. When we are experiencing "flow," the passage of time changes and our sense of self in the world changes. We wonder if Simms has considered Csikszentmihalyi's theory of flow and how it mirrors the many aspects of child dwelling that she examines in her book.

EVA'S RESPONSE: First I wanted to respond to your reading of the "afternoon" example above. I actually agree with you that for the child the word "afternoon" signified an event (time after taking a nap), but the significance of this discussion is that there are intuitive temporal sequences which even young children understand and by which they judge the unfolding and sequencing of events. Temporal words, such as today, yesterday, and tomorrow, or even the days of the week are fairly abstract and young children "get" them when they can be tied to actual happenings in their lives.

The example of your son saying to his brother "When I'm older than you, I'm going be the one to go first" is about time: he uses a very sophisticated temporal grammatical construct to imagine something that will be happening in the future, and that then will have permanent consequences. In his world, older is not a fixed temporal relation, but one that is shifting and moveable: one day he will be older and more powerful. In his pre-operational time, however, his brother does not age at the same time and speed. On the level of grammar, which is used here pre-reflectively and intuitively, this child already has an understanding of the future, of possibility, and of duration, while on the level of cognitive temporal concepts time is still episodic and fragmented and lacks the homogenizing order of Piaget's operational time.

As to the notion of flow: I think that flow is an intense bodily attunement to a particular situation where the senses, the movement of the body, the mind's attention, and the experienced environment fit together and form a chiasmic event. It characterizes a state of consciousness that is completely absorbed by and aware of its intended perceptual environment. My children spent hours building a set of rooms and tunnels out of boxes and blankets and setting up and furnishing a small city. I think that children have a greater capacity to experience flow, particularly in play, because they are more willing to give themselves over to the call of things and engage them with all their senses.

\section{CHAPTER SEVEN: Babble in the House of Being - Pointing, Grammar, and Metaphor in Early Language Acquisition}

"When the baby is born, will it speak English or French?" asked my 5 year old son before his little brother was born. Although ours was an English-speaking household, Douglas was attending a French Immersion kindergarten, so the two languages were part of his life. And so his question was reasonable, although, like so many young children's questions, it was at first baffling and then thought-provoking. Had I read Simms' book before I was asked that question, I would have had more information about a baby's experience and development of language and the wondering that my older son's question sparked in me would have found some answers. In chapter seven of her book, Simms reviews much of the research on earlylanguage acquisition. She paraphrases the work of Werker and Tees indicating that "after only a few days, newborns recognize and prefer the sound pattern of the language that is 
spoken around them, and that by eight to twelve months they narrow down their ability to discriminate between the phonemes of all language to just the sounds used in their mother tongue” (p. 168). Simms also reviews young children's "creation” of grammar, which surely resonates with any adult who has heard a child exclaim that he "runned" down the road.

QUESTION: Simms' examination of the gesture of pointing interested me. The ability to point, and thus invite another into a conversation about something that is too far away to touch, was a baby's action that I had not previously considered as an important accomplishment. After reading Simms' book, I was impressed by the complexity of the gesture of pointing. Once again, the competence of the young child was highlighted to me. I relayed some of the significance of the gesture of pointing to two soon-to-be grandmothers, and I suggested that they should be watching for this gesture to emerge when those grandbabes were reaching the end of their first year of life. I suspect that others who read Simms' book will find bits to pass along to yet more adults who have young children in their lives. We would like to ask Eva what other readers have found to be memorable in her work? Does she know if readers pass along interesting facts and ideas?

EVA'S RESPONSE: I very much liked your phrase about the surprise about "the competence of the young child.” What I hear from parents after they read my book is an appreciation for the complexity of the child's world, but also how careful observations of the spatial, temporal, and co-existential structures of their children's lived situations allows them often to understand what is going on more fully and respond more helpfully. I have worked with a number of parents to solve small problems, like a baby's inability to fall asleep, or a four year old's emotional meltdown when coming home from pre-school. Together we looked at the actual structures of the bedtime experience or the transition home from school and changed a small perceptual event, such as the posture of the baby in the crib, or the creation of a small holding/hiding space for the pre-schooler to decompress and make the transition out of the stress of the school environment.

I think that a phenomenological attunement to the child's world empowers parents: they themselves can begin to see and understand the problems their children encounter and help them find solutions. The pedagogical goal of my book is to show the competence of children, but also to show parents that they themselves have the competence to guide their children and make their own decisions about the welfare of their families. I hope that in the end they don't see my book as another "expert manual" in parenting which tells them what to do, but as an inspiration to change their own way of looking at children so that they don't need the “experts” anymore.

\section{CHAPTER EIGHT: The Invention of Childhood - Historical and Cultural Changes in Selfhood and Literacy}

Stop being a child, that's so child-like, when I was a child, that's childish, you're such a child and I know we can go on with child phrases that tend to be deeming or something other than adultish. I converse with many adults in my professional work about what it means to be a child. Childhood is often the center of focus in my everyday life as a father and teacher educator. I find relative ease in defining characteristics that I expect of children's behaviours, attitudes, and to put it simply their way-of-being in the world, but I am uncertain if any of these conversations really capture what it means to experience childhood? Quite often adults will reflect on past significant moments (as we did at the beginning of this review) from their childhood to qualify an answer, explanation, or definition. However, we tend to explain past 
experiences from an adult's perspective of the world and to claim this is sufficient would be disingenuous and even insulting I think to all children. Even when I ask the many children I have encountered (including my own) what is childhood they will attempt to explain their reasoning using examples of what it is not by adult examples: when I grow up I ...

Simms tackles childhood by calling it an invention (see p. 195) that had its origins in the city of Cologne in 1213 during a historic event that became rumoured as the Children's Crusade. History purports that in excess of "twenty-five thousand children left their homes to follow a charismatic youth" (p. 196) aiming to march to the Holy Land-most never succeeded or survived the event. Simms uses this historical report as a means to establish “children's lives ... [as] woven into the structures of adult existence” (p. 196). Simms asks a profound question: What is the relationship between adults and children?

Simms calls this crusade an obscure moment and despite the challenge to learn more of this historical event in determining a more deeper portrayal of childhood pushing social conventions, I have not been able to do so (see Cahill, 2006, p. 166). Regardless, Simms pushes me to struggle with what I concretely explore in present day: the dualism between mature and immature (p. 199). Simms states that "the child is only childlike in comparison to what is not childlike (van den Berg, 1961, p. 32). Simms positions many aspects for us to move past phenomenologically: stature, social attitudes, art, cultural expectations, economics, family conventions, and maturation-emotionally and biologically. With all these possible ways to see what it means to be a child, Simms draws our attention to an evolutionary realization: "The adult world is no longer a world safe for children, and adult life has become so complex and difficult that it takes children almost decades to catch up with their elders” (p. 211). Thus whether childhood is a social-cultural convention or invention, Simms clearly articulates that to be a child is unique and distinct from an adult. And as adults we need to do more to preserve and protect the fragility of childhood in times of competing interests-education being one of them. Therefore, the approach adults need to take when encountering children is to be pedagogical-a relational watchfulness—a social vigilance.

QUESTION: From your historical stance taken in this chapter do you feel Western society has lost its pedagogical way of being with children? Do you think it is possible for adults to reclaim a more pedagogical way of being with children despite competing agendas of the world? Should adults accept the complexities and resolve our professional energies to better prepare children to face the challenges of the world head on and move past childhood inventions?

EVA'S RESPONSE: It seems to me that each generation of adults has to re-invent the pedagogical way of being with children. Implied in this is a paradox. On the one hand, we have to create a form of care for the young that allows them to flourish in their particular society and reach the kind of adulthood that allows their culture to renew itself. On the other hand, care for children demands that we have to be vigilant against the excesses and dangers of our cultural institutions and protect our children from unreasonable or damaging demands and practices. The truly pedagogical way zig-zags (to use Husserl's term) between a phenomenological attunement to the child as a being in a particular world, and a critical understanding of the cultural production of childhood (and adulthood) through family structures, educational institutions, and the political and scientific discourses of our time. 


\section{Conclusion}

Many years ago, I read: “The best preparation for being six years old is 365 days of being five years old. The best preparation for being five years old is 365 days of being four years old.” I do not know who to credit for this sentence, but I have repeated it over and over again in a sort of defence for a young child's right to experience life in the fullest way and not to be rushed through the early years. Too often, particularly in fields of care and education, the daily experience of the young child is considered preparation for life, not life itself.

The questions lurking behind the above quote are: What is 365 days of being five years old all about? What is 365 days of being four years old all about? For that matter, what is 365 days of being two years old all about, or what is 24 days of being alive all about? Eva Simms, in her book The Child in the World: Embodiment, Time, and Language in Early Childhood offers the reader a glimpse into the possible answers to those questions. She provides ideas from many other researchers and philosophers. She adds interpretation based on her own years of watching children with an eye to their lived experience-she dwells as a sensitive academic and caring adult. In reading Simms' book, one is certainly led to re-frame the child's world. The child becomes competent. The adult becomes an influential partner.

Simms' book is not exhaustive. For example, she has not included references to the world-renowned and highly influential early childhood programs in Reggio Emelia, Italy. The philosophy of the Reggio Emelia approach revolves around the child as competent, and so, this is a rather important link that Simms has not made. Simms' book is also not free from questionable interpretation (of children's art), judgement (about American parents), and bias (about Waldorf education). However, Simms book holds great potential to change an adults' stance on the lived experience of a child, and, as such, it is an important and powerful text.

\section{References}

Bachelard, G. (1983). Water and dreams: An essay on the imagination of matter. Dallas, TX: The Pegasus Foundation.

Chawla, L. (2003). Special place -- what is that? Significant and secret spaces in the lives of children in a Johannesburg squatter camp. In E. Goodenough (Ed.), Secret spaces of childhood. Ann Arbor, Michigan: The University of Michigan Press.

Csikszentmihalyi, M. (1990). Flow: The psychology of optimal experience. New York: Harper Collins.

Heidegger, M. (2001). Zollikon seminars: Protocols - conversations - letters (F. Mayr \& R. Askay, Trans.). Evanston, Ill: Northwestern University Press.

Louv, R. (2008). Last child in the wood. New York: Workman.

Merleau-Ponty, M. (1964). Bullentin de Psychologie, 17(236), 107-336.

Merleau-Ponty, M. (1964b). The primacy of perception. Evanston: Northwestern University Press. 
Merleau-Ponty, M. (2010). Child psychology and pedagogy (T. Welsh, Trans.), Evanston, Ill: Northwestern University Press.

Rothfuss, P. (2007). The name of the wind. NY: DAW. Retrieved from http://www.goodreads.com/quotes/show/94979

Simms, E. (2010). Questioning the Value of Literacy: A phenomenology of speaking and reading in children. In K. Coats et al. (Eds.), Handbook of Children's and Young Adult Literature (pp. 20-32). London/New York: Routledge.

Simms, E. (2008). The child in the world: Embodiment, time, and language in early childhood. Detroit, MI: Wayne State University Press.

Simms, E. (2008b). Children's lived spaces in the Inner city: geographical and political aspects of the psychology of place. The Humanistic Psychologist, 36(1), January 2008, pp. 72-89.

Truffaut, F. (Director). (1976). Small change [Motion picture video]. United States of America: MGM Home Entertainment.

Van den Berg, J. H. (1961). The changing nature of man. New York: W.W. Norton.

Van Manen, M. (1982). Phenomenological pedagogy. Curriculum Inquiry, 12(3), 283-299.

Van Manen, M. (1991). The tact of teaching: The meaning of pedagogical thoughtfulness. New York: State University of New York Press.

Van Manen, M. (2002). The tone of teaching. London, Ontario: Althouse Press.

Van Manen, M. (2006). Reflectivity and the pedagogical moment: The practical-ethical nature of pedagogical thinking and acting. In I. Westbury and G. Milburn (Eds.), Making curriculum strange (pp.49-78). London: Routledge.

Williams, M. (1922). The velveteen rabbit: Or how toys become real. Retrieved from http://digital.library.upenn.edu/women/williams/rabbit/rabbit.html 